\title{
The Hopkins-Nanjing Center for Chinese and American Studies
}

\author{
By Diane K. Harvey \\ Collection Development Librarian \\ Johns Hopkins University-SAIS
}

\section{A cooperative effort in international librarianship.}

W hen the Hopkins-Nanjing Center for Chinese and American Studies opens in Nanjing, China, in September 1986, its library will be ready to serve the American and Chinese students and faculty of this innovative venture in international cooperation. The 20,000-volume library represents a unique resource available not only to the Center, but also to scholars in the entire east central region of China.

As one of the first equal partnerships between Chinese and American universities, the HopkinsNanjing Center represents a step beyond the cultural and educational exchange programs that have flourished since normalization of relations in 1979.

Nanjing University is considered one of the top universities in China, and has an enrollment of more than 6,000 students in fifteen liberal arts and natural science fields. It is located in the city of Nanjing in east central China.

The link between The Johns Hopkins University and Nanjing University was initiated by a Hopkins faculty member, Chien Chih-yung, who is also an honorary professor at Nanjing. An academic partnership had been in place for several years, and during a visit to Nanjing in 1981, Hopkins administrators raised the subject of building a permanent facility on the Nanjing campus. Once the State Council of the PRC approved the project, planning moved quickly. Architects from both countries developed a design that includes classrooms, offices, living areas, a language laboratory and dining facilities, in addition to the library. Construction began in September 1984 and is expected to be completed in time for the September 1986 opening.

The Center's major purpose is to train Chinese and American students for careers in diplomacy, journalism, commerce, and other fields. The curriculum stresses international relations, economics, political science and modern history. American students will work in Mandarin Chinese, studying subjects such as Chinese diplomacy and trade law with Chinese faculty members. American faculty will instruct Chinese students in English on topics such as U.S. foreign policy and contemporary American society. Most Center students are to have master's degrees and they must be fluent in the language of instruction. Beyond the training of graduate students, the center will serve as a resource for visiting scholars and traveling delegations.

The center is jointly administered by the two universities. The resident co-directors are Leon Slawecki and Wang Zhigang. William Speidel of the Hopkins School of Advanced International Studies (SAIS) in Washington, D.C., is the Hopkins-Nanjing project director in the United States. SAIS is responsible for recruiting American faculty members and students, as well as handling curriculum and library matters for Johns Hopkins University.

A key component of the center is its library, 
which will not only support the curriculum and research work of the resident faculty and students, but provide what has been termed a "regional information center" for scholars throughout Jiangsu Province and east central China. Designed by U.S. and Chinese architects, the library will have stack areas, seating for twenty-four, a public services desk, two photocopying machines and space for microform reading and storage.

On opening day, the library will contain 20,000 volumes, half in Chinese and half in Western languages. Each year the two sponsoring universities together will add 4,000 volumes. Four hundred periodical subscriptions have been placed. The library will be staffed by Chinese professionals and support personnel, but western-language material selection, as well as consultation, is provided by the SAIS staff in Washington, D.C. Peter Promen, director of SAIS's Mason Library, is the principal librarian involved with the project. Ma Xian-zhen of the Nanjing University Library will oversee the Center's library, although it is not a part of the Nanjing University library system.

Coordination with an overseas library is not new to Hopkins, since the SAIS library performs similar functions for the Bologna Center, a graduate program in Italy. The Bologna Center, however, is administered solely by SAIS, while the HopkinsNanjing Center is a cooperative venture with a more complex interlibrary relationship.

One of Hopkins' major responsibilities has been the development of the core collection of 10,000 western-language (primarily English) volumes. Material selection is the primary responsibility of Diane Harvey, former head of the Government Publications/Maps/Law Department of Johns Hopkins' Eisenhower Library. Because the Center's faculty had not been selected at the start of the project, a SAIS faculty committee, chaired by noted China scholar A. Doak Barnett, helped define the scope of the collection. In order to provide curricular support, the library has acquired core material in international relations, economics, political science and American history. American studies materials, including books on current social issues and popular culture, have also been included. Western-language books about China make up only about $15 \%$ of the collection, since American students will be expected to use Chineselanguage materials in their studies. A reference collection, which may be expanded in the future to cover additional subject areas, supports the core collection. The Chinese language materials parallel the western-language collection.

Blackwell North America (B/NA) was selected as the library's vendor on the basis of its excellent record in supplying books to libraries in China since 1981. B/NA is able to ship directly to the Center and bill to the SAIS library in Washington. SAIS has been quite successful in acquiring out-of-print titles for the Center; this is crucial to establishing a core collection. Out-of-print and gift titles are

\title{
Midwest Library Service
}

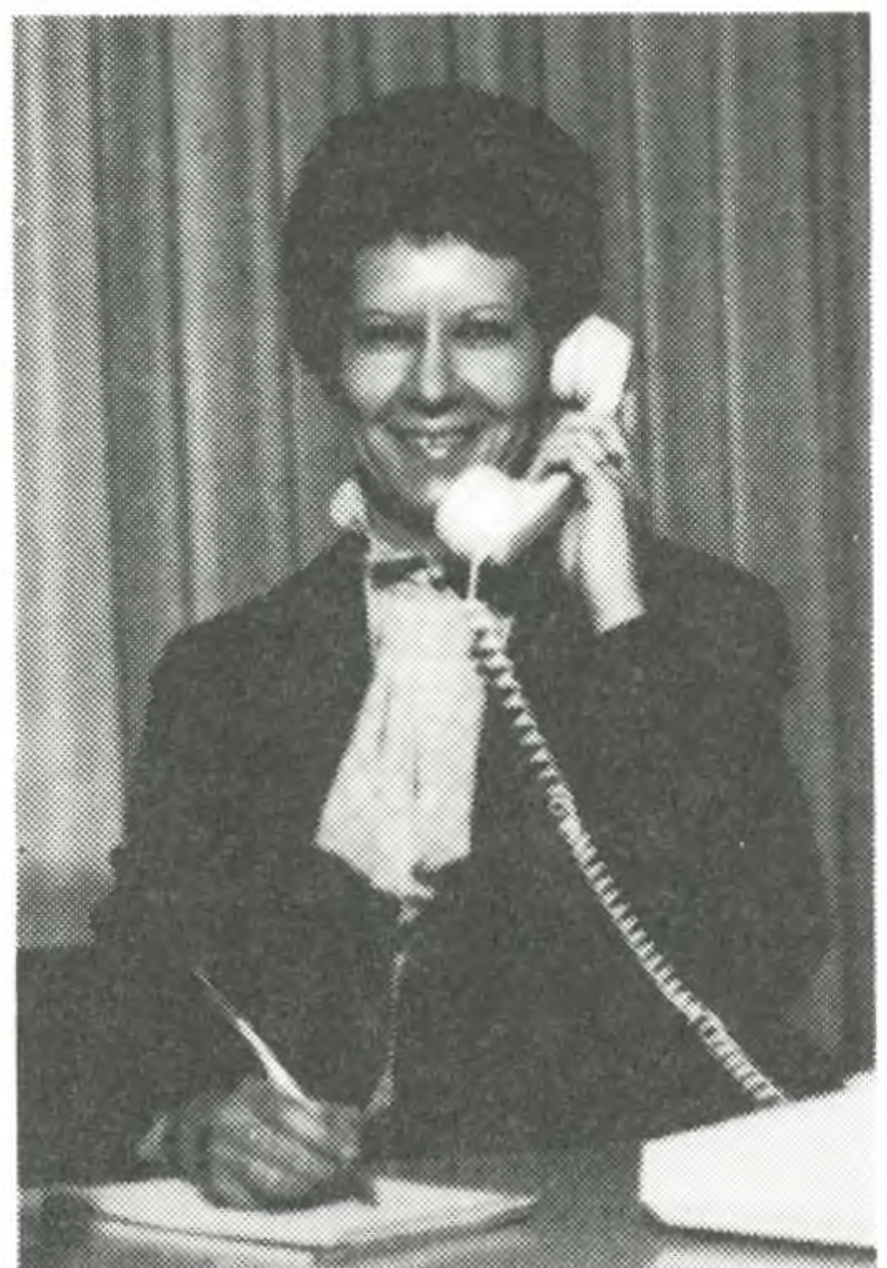

\author{
You won't find more \\ personal attention \\ ... anywhere
}

College and university librarians: We have what you're looking for. While Midwest utilizes state-of-the-art computer systems, we realize machines can't do it all. So when you want to place an order, ask a question, or discuss a problem, you can call direct on Midwest's toll-free WATS line and conduct business on a nameto-name basis with your personal customer service representative. It's the kind of attention that Midwest has provided to college and university libraries for 24 years.

Call toll-free (800) 325-8833

Missouri librarians call toll-free (800) 392-5024 Canadian librarians call collect (314) 739-3100 


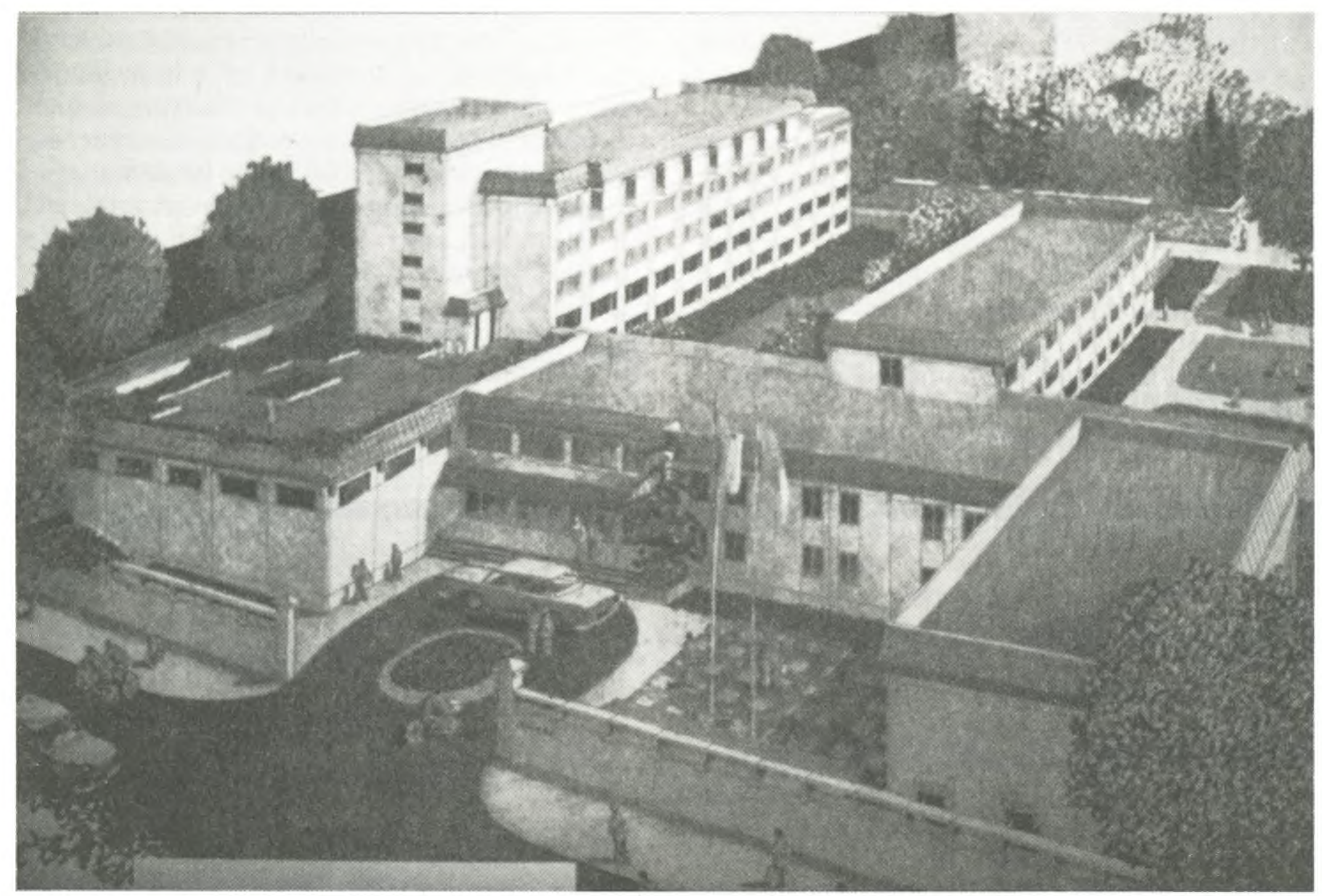

Artist's rendering of the Hopkins-Nanjing Center for Chinese and American Studies. Library occupies the ground floor of the three-story wing (upper right).

shipped by SAIS to Nanjing.

A variety of selection methods has been used to build the collection. Books for College Libraries and Choice's Opening Day Collection were invaluable for selecting core titles, and the high rate of fulfillment on out-of-print orders made use of those tools viable. Specialized bibliographies and course syllabi from Johns Hopkins University were a major resource. B/NA's New Title Advisory Service has been a primary source of current titles, along with tools such as Choice, Foreign Affairs, American Political Science Review and the Journal of Economic Literature. As faculty from around the U.S. were recruited to teach at the center, their suggestions were solicited.

Gifts comprise approximately $15 \%$ of the total volumes, although this percentage is expected to decline in future years. These gifts include a significant selection of titles from the personal collection of Norman Graebner, an eminent scholar of American diplomatic history at the University of Virginia.

Johns Hopkins, after consultation with the Chinese librarians who will staff the library in Nanjing, will provide card catalog sets using Library of Congress classification, through Blackwell North America. OCLC printouts are sent to Nanjing from the SAIS library for items which cannot be located through B/NA's data base. It appears that only $3-5 \%$ of volumes supplied will require original cataloging by the library's staff.
Automation of library functions is still in the early stages, with the goal of providing an integrated online system in the future. Several pilot projects are underway, including using an IBM PC-AT with INMAGIC software to create a model for database management. Library automation is a prime interest of the center's administration, and Robert Gresehover, deputy director of Johns Hopkins' Welch Medical Library, is actively involved in its development.

Differences between Chinese and American philosophies of librarianship are most evident in the area of public services. Chinese libraries have traditionally exhibited a "caretaker" approach to library collections, an outgrowth of both the traditional Chinese reverence for knowledge and the need to preserve scarce resources in a developing economy. The American user-oriented philosophy is not widely evident in Chinese academic libraries. Because the American students and faculty have very different expectations for library services, it is hoped that the Center's library will demonstrate a strong service attitude. For example, the reserve function is virtually unknown in China, where students rely on textbooks and notes provided by instructors. Reserve material for the library will be supplied in the first year by the SAIS library, but provision of services will be the job of the Center's staff. Reference and interlibrary loan are two other areas in which the expectations of Chinese and American users must be accommodated. The Cen- 
ter's library will have a cooperative relationship with the libraries of the Nanjing University system, and Center students will be able to use those extensive collections.

To further the Hopkins-Nanjing relationship, and to provide information about current American library practices, there has been a series of short-term consultantships between the universities. Visits in 1981-1982 by Nanjing University administrators included tours of Hopkins libraries, and several trips by Hopkins librarians to Nanjing have focused on planning for library functions, automation and public services.

This kind of consultation has been essential in the development of a library in a cooperative international setting. The opportunity to create an academic library "from the ground up" is in itself unusual. Even more unusual is its structure, which required international communication on every aspect of library service. All the basic issuescollection development, bibliographic control, automation, space planning and public services - had to be considered from a unique bicultural perspective. Just as the Center is a pioneering venture, so the library represents a cooperative approach that will try to combine the best aspects of Chinese and American librarianship.

\title{
Checklist for closing
}

\section{a college library}

\author{
By the CLS Ad Hoc Committee on Closing Colleges (1984-85) \\ John Sheridan, Chair
}

\section{How to close your library gracefully.}

\begin{abstract}
T he announcement that a college, and thus its library, is closing, however much expected, will come as a shock. This checklist and narrative are designed to provide the librarian and college administrator with information about the things that need to be done to close and dispose of the library in an orderly fashion. The timeframe for closing may not allow for the entire checklist to be implemented, but the persons involved can be aware of what is or is not being done. Experience has shown that greater benefits accrue to the institution if a librarian familiar with the collection supervises the entire process.

A helpful summary of five college library closings will be found in Mary Ann Griffin's "When a Library Closes," Journal of Academic Librarianship 10 (July 1984):141-45.
\end{abstract}

\section{Checklist}

I. Determine the nature and value of the collection 1. If there is time, conduct an inventory of the collection and then use the shelflist as the standard for the contents of the collection.

2. Prepare an evaluation statement on the scope of the collection, including a list of subject strengths with level of development, and a list of special collections.

3. Check state and federal regulations (e.g., document depositories, HEA and Title II-A) for restrictions, and local and regional collection agreements, and list items involved.

4. List gifts with stipulations, if any.

5. Identify and remove for safekeeping valuable items (including suspected "last copies"). 